\title{
Effectiveness of Fluid Milk Advertising since the Dairy and Tobacco Adjustment Act of 1983
}

\author{
Ronald W. Ward; Bruce L. Dixon \\ American Journal of Agricultural Economics, Vol. 71, No. 3. (Aug., 1989), pp. 730-740.
}

Stable URL:

http://links.jstor.org/sici?sici=0002-9092\%28198908\%2971\%3A3\%3C730\%3AEOFMAS\%3E2.0.CO\%3B2-M

American Journal of Agricultural Economics is currently published by American Agricultural Economics Association.

Your use of the JSTOR archive indicates your acceptance of JSTOR's Terms and Conditions of Use, available at http://www.jstor.org/about/terms.html. JSTOR's Terms and Conditions of Use provides, in part, that unless you have obtained prior permission, you may not download an entire issue of a journal or multiple copies of articles, and you may use content in the JSTOR archive only for your personal, non-commercial use.

Please contact the publisher regarding any further use of this work. Publisher contact information may be obtained at http://www.jstor.org/journals/aaea.html.

Each copy of any part of a JSTOR transmission must contain the same copyright notice that appears on the screen or printed page of such transmission.

The JSTOR Archive is a trusted digital repository providing for long-term preservation and access to leading academic journals and scholarly literature from around the world. The Archive is supported by libraries, scholarly societies, publishers, and foundations. It is an initiative of JSTOR, a not-for-profit organization with a mission to help the scholarly community take advantage of advances in technology. For more information regarding JSTOR, please contact support@jstor.org. 


\title{
Effectiveness of Fluid Milk Advertising Since the Dairy and Tobacco Adjustment Act of 1983
}

\author{
Ronald W. Ward and Bruce L. Dixon
}

\begin{abstract}
An econometric model pooling monthly cross-sectional and time-series data is estimated to measure the impact of national and regional generic fluid milk advertising. The estimated model shows that the effectiveness of advertising has increased since the implementation of the Dairy Adjustment Act. Gains in fluid milk sales attributed to milk advertising are estimated. Sales gains for both the pre- and post-act periods are shown along with the gains associated with parameter changes in the post-act periods. Marginal advertising responses are derived.
\end{abstract}

Key words: advertising effectiveness, Dairy and Tobacco Adjustment Act, econometric model and simulation, fluid milk.

Over the last decade the impact of advertising as a means of promoting agricultural commodities has received considerable interest. Perhaps the most ambitious promotion campaign for agricultural products has been undertaken by the National Dairy Promotion and Research Board (hereafter referred to as the Board). Under the National Dairy and Tobacco Adjustment Act of 1983, all dairy farmers must pay an assessment of all milk produced for commercial use. These funds are used to support dairy advertising, research, and nutritional education. For the periods from September 1984 through September 1987 , the Board spent the equivalent of $\$ 78.9$ million on television advertising for fluid milk (Ward and Dixon 1988). ${ }^{1}$ In addition, regional organizations funded promotional campaigns. For the twelve milk regions considered in this study, \$43.6 million was spent on regional generic milk advertising on television and

Ronald W. Ward and Bruce L. Dixon are professors of agricultural economics at the University of Florida and the University of Arkansas, respectively.

Florida Agricultural Experiment Station Journal Series No. 9644.

The authors acknowledge the full financial support of the National Dairy Promotion and Research Board and the assistance of Mrs. Karen Roepken, United Dairy Industry Association. Appreciation is extended to the Dairy Oversight Committee, A. D. Little, Inc., AMS-USDA, and two reviewers for their constructive comments. The findings do not necessarily reflect the views of the organizations acknowledged.

${ }^{1}$ The equivalent includes direct expenditures on fluid milk advertising and a prorata share of the calcium advertising which is attributed to fluid milk. radio between September 1984 and September 1987.

Is generic promotion a viable method for increasing the demand for agricultural products? While this question has been examined before (e.g., Ward and Myers, Thompson and Eiler, Kinnucan and Forker), none of these studies have dealt with nationwide campaigns coordinated at a national level. Because of the size of the Board's budget, campaigns can be undertaken that likely go beyond the resources of the smaller regional campaigns and potentially generate higher quality advertisements. Thus, the hypothesis of interest is whether a national dairy promotional program has increased milk consumption and strengthened the overall effectiveness of dairy advertising. The analysis is accomplished by estimating a demand model for fluid milk with media (television and radio) advertising expenditures included as an explanatory variable.

Prior dairy advertising studies have typically estimated models for one specific region. Thompson and Eiler estimated separate models for each of three different SMSAs in the state of New York. Kinnucan and Forker, and Liu and Forker estimated models using data for New York City. Ward and McDonald took a different approach, estimating the demand for fluid milk by pooling data from ten separate U.S. milk market regions.

In this study, monthly data from twelve milk 
market regions, covering about $40 \%$ of the U.S. population, are pooled. A brief review of the Board's activities is presented, and then an econometric model of fluid milk demand is specified and estimated. In the final section simulated sales gains attributed to fluid milk advertising are shown for both pre- and postact periods.

\section{The National Dairy Board Program}

The national dairy promotional programs are supported by a checkoff requiring dairy farmers to contribute a total of $15 \notin$ per hundredweight of fluid milk produced for commercial use. Five cents must go to the Board, while credits up to $10 \varnothing$ for regional, state, or local dairy advertising and nutritional education programs can be used to satisfy the remainder of the $15 \varnothing$ assessment (U.S. Department of Agriculture). The Board operates independently of the regional and state groups and has national coverage. Figure 1 shows monthly media advertising expenditures for the twelve regions and the Dairy Board's national fluid milk advertising for periods start- ing with December 1978. The pre-act periods are those months before September 1984. Post-act periods include all months since September 1984, inclusive. During the pre-act months, the twelve-region expenditures approached $\$ 19$ million annually. The Dairy Board expenditures are for fluid milk and milk related calcium advertising since September 1984. While the Board's programs are national, figure 1 shows the Board's expenditures for fluid milk in total and on a prorata basis to the twelve regions. As evident in figure 1 , the regional expenditures declined during the post-act periods.

A comparatively recent phenomenon is the hypothesis that sufficient levels of calcium lessen the incidence of osteoporosis. The Board has acted upon this hypothesis in its advertising campaigns. While the calcium advertisements refer to a variety of dairy products, part of the calcium advertising is expected to stimulate milk sales because approximately $75 \%$ of calcium advertising emphasizes fluid milk (Ward and Dixon 1988). Thus, $75 \%$ of the expenditures on calcium advertising is considered part of the Board's total fluid milk advertising effort.

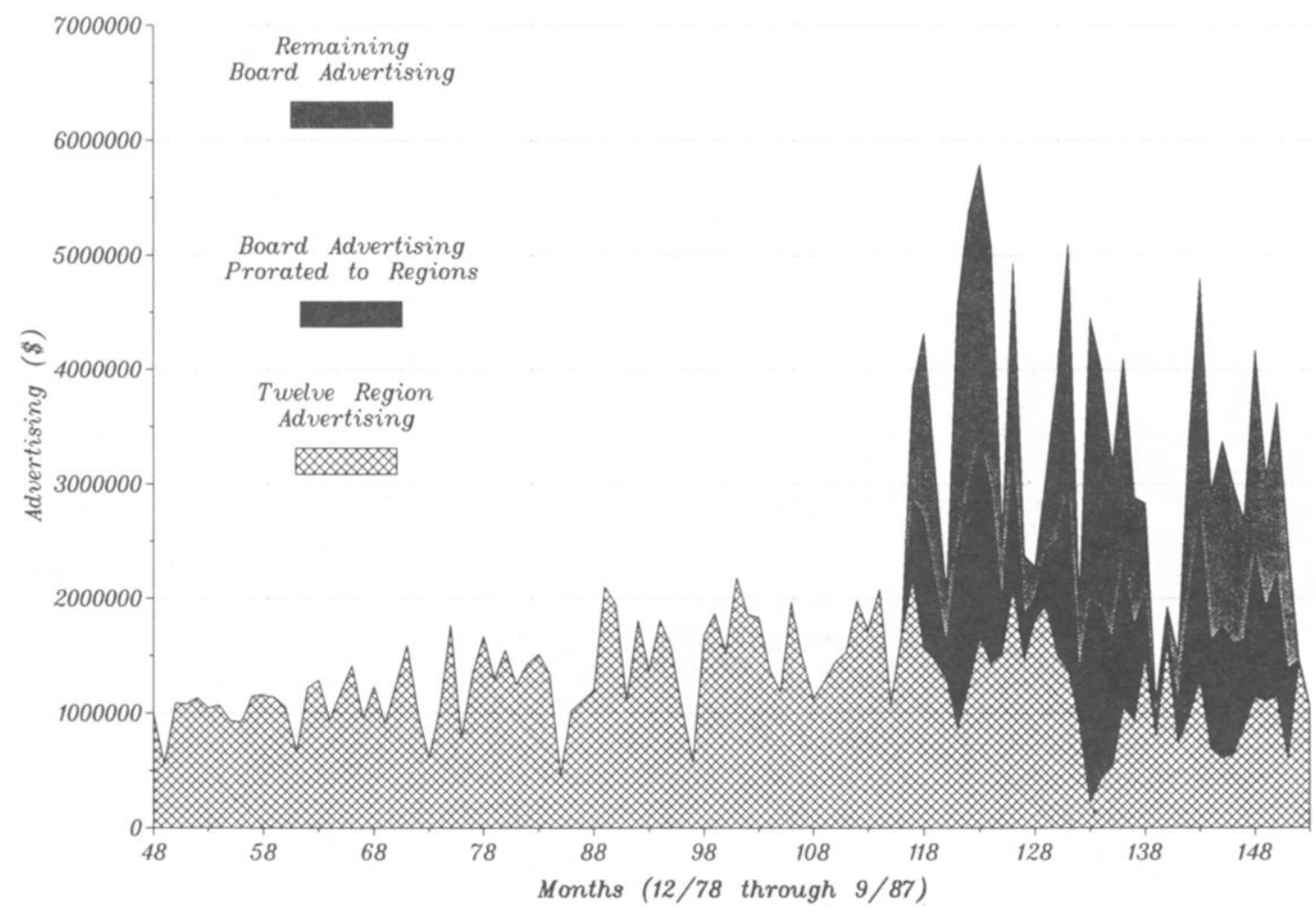

Figure 1. Regional and National Dairy Board fluid milk advertising expenditures 
The Board's programs represent a substantial increase in advertising efforts beyond existing regional expenditures. These programs are designed to establish long-term changes in the demand for fluid milk, with product attributes being the primary focus of the media messages. Given the expected carryover effects of the advertising and the increased efforts since September 1984 (i.e., post-act periods), it is reasonable to expect that the relationship between advertising levels and the resulting responses has changed. The subsequent model is designed to test this adjustment hypothesis.

\section{Advertising Model Development}

In several past studies of the demand for fluid milk, own price, income, and the level of advertising are explanatory variables. Advertising often enters the model assuming that a carryover effect exists. In studies using monthly data, shifters for seasonality are entered to account for seasonal components in milk consumption. Prices of substitutes are usually included as well as demographic characteristics (Kinnucan and Forker, Ward and Davis).

In the present analysis the dependent variable is average daily ounces of fluid milk consumed per capita in a region $(M L K Q)$. $M L K Q$ is assumed to be a function of deflated per capita income by region $(D I N C)$; deflated market administrator retail price of fluid milk per one-half gallon $(M L K P)$; price of orange juice $(O J P R)$; current and lagged television and radio advertising per capita deflated by appropriate media cost indices $(D A D V)$; a variable representing trend effects increasing monotonically each month $(T I M E)$; seasonal shifters; and six variables reflecting demographic differences among the twelve regions. Eleven monthly binary variables (DJAN, $D F E B, \ldots$. .) are included to account for seasonal effects. The six demographic variables include: (a) proportion of a region's population that is under eighteen years of age $(N U 18) ;(b)$ proportion of a region's population that is female $(F E M L) ;(c)$ proportion of a region's population that is black $(B L C K)$; $(d)$ proportion of a region's population that is rural $(R U R L) ;(e)$ proportion of households that contain only one person, i.e., family size $(F M S Z)$; and $(f)$ the median number of years of schooling among people over the age of twenty-five years $(S C H L){ }^{2}$

Positive coefficients are expected for $N U 18$, $F E M L$, and $S C H L$. Younger consumers have a stronger demand for dairy products, and women are likely to as well because of calcium concerns. Similarly, milk consumption probably increases with education, primarily because of nutritional awareness. Studies show that blacks have a higher level of intolerance to lactose (Goodhart and Shils); thus, a negative sign is expected for $B L C K$. Consumption habits and alternative supply sources other than commercial channels may differ among rural and urban consumers, indicating a negative sign for $R U R L$. Larger families may view milk as a low cost protein source, indicating a negative sign for FMSZ. However, the hypothesized signs for both $R U R L$ and FMSZ are not as clear as with the other variables. Because the observations on these variables change slowly over time within a region, the inclusion of these variables helps explain regional differences when pooling cross-sectional data.

The variable $O J P R$ accounts for the effects of another product closely associated with breakfast consumption. Orange juice may be a complement or substitute good for fluid milk because it can be consumed along with milk as part of a balanced breakfast or consumed in place of milk as a beverage. Other price series corresponding to the monthly regional data, such as for soft drinks, were not available. Furthermore, Ward found that cola prices were insignificant, and Kinnucan found that coffee had a low but significant cross-price elasticity in the New York market.

The deflated advertising variable $(D A D V)$ includes both regional and Board expenditures. Per capita advertising is calculated by expressing each region's expenditures on a per capita basis $(A R E G)$ within each region. The Board's expenditures are expressed on a national per capita basis $(A B R D)$ and then added

\footnotetext{
${ }^{2} S C H L$ is a weighted mean of county medians within a region. The regional data and advertising expenditures were drawn from several unpublished data sources. Regional sales, advertising, and income were tabulated by United Dairy Industry Association; Board advertising data were from the National Dairy Board's accounting files; California data were provided by McCann-Erickson Advertising Agency. The income observations were based on quarterly personal income by state from the Bureau of Economic Analysis, Department of Commerce. Milk prices were taken from unpublished AMS-USDA Market Administrator price reports for selected cities. Demographic data were taken from various U.S census tapes and interpolated and extrapolated over the non-census months.
} 
to each region's per capita expenditures. Regional expenditures are deflated by regional indices, while the Board's advertising expenditures are deflated using a national index of television rates. While the study does not differentiate between the radio and television media, the deflators do account for the media mix since deflation indices show considerable difference between radio and television.

The twelve regions consist of ten federal market orders and two regions not under a federal order. The federal order regions are eastern Colorado (no. 137), southeastern Florida (no. 13), Georgia (no. 7), Utah (no. 136), Greater Kansas City (no. 64), southern Michigan (no. 40), New England (no. 1), Middle Atlantic (no. 4), Texas (no. 126), Upper Midwest (no. 68). California and most of Virginia make up the final two regions.

A double log model is used as in Ward and McDonald and in Kinnucan and Forker. A twelve-month, second-degree polynomial lag model on advertising is specified with both ends of the lag structure constrained to zero. Several lag structures were evaluated including restricted and unrestricted end point specifications. The lag patterns were quite similar across the alternatives. The advantage of the end point restrictions is that only one parameter $\left(\delta_{1}\right)$ need be estimated and, hence, it is much more convenient to deal with in measuring changes in the advertising effectiveness over time (Ward and Dixon 1987, p. 69). The final model end point restrictions were with lag periods of minus one and twelve months.

The advertising variable defined in equation (1) includes both regional and Board expenditures with both expressed on a deflated per capita basis. The values for $W_{j}$ in equation (1) below correspond to the weights associated with the twelve-month polynomial lag (i.e., $j$-lags) with end point restrictions (Ward and Dixon 1987). The parameter $\Gamma$ is needed because there are months in the early period of the data set when no advertising occurs. Also, some underlying goodwill exists that can be partially reflected with $\Gamma$ (Bozgodan et al.). Because the model takes logarithms of advertising, a positive value for $\Gamma$ is required. ${ }^{3}$ Subscripts $i t$ denote the $i$ th region for time period $t$.

\footnotetext{
${ }^{3}$ The actual value of $\Gamma$ is selected by estimating all of the other coefficients for a given value of $\Gamma$, using estimated generalized least squares. This process is repeated for different $\Gamma$ values and the resulting mean square error $(M S E)$ for the estimated equation is recorded. That $\Gamma$ giving the minimum $M S E$ is then selected.
}

$$
\begin{aligned}
\mathrm{LN} D A D V_{i t}=\Sigma_{j} & \left(\left(\operatorname { l n } \left(A R E G_{i(t-j)}\right.\right.\right. \\
& \left.\left.\left.+A B R D_{i(t-j)}+\Gamma\right)\right)^{*} W_{j}\right) .
\end{aligned}
$$

\section{Structural Shift}

A major hypothesis for the current research is that the Board's programs have led to structural shifts in consumption habits. Increased expenditures should result in additional consumption assuming positive effects from the advertising. Given adequate time and continuity of effort, the programs also may lead to increases in the advertising coefficients. A shift in the advertising coefficient $\left(\delta_{1}\right)$ over time is the most direct impact, but the Board's activities may also have affected the coefficients of the other explanatory variables. Binary shifter variables are used to allow some coefficients to vary from one period to another to check for structural change. ${ }^{4}$ Identifying the points when such shifts occur is important. While statistical procedures to search for shift points (Frank) are available, a preferable procedure is to rely on prior knowledge of the process being observed to indicate when such shifts should occur. For this study an obvious point is when the Board began advertising activities, i.e., September 1984.

Structural change is tested by allowing the selected coefficients to change in three intervals. The first interval extends from September 1984 through July 1985. The second interval spans August 1985 through September 1986. The final period includes the months from October 1986 through September 1987. These intervals were selected through preliminary testing and an evaluation based on the general advertising expenditure cycles during the post-act periods. Also, these ranges gave the minimum MSE relative to other plausible designations of the intervals.

The structural shifts are modeled using discrete shift variables. Define

$$
\begin{aligned}
T 1_{i t} & =\left\{\begin{array}{l}
1 \text { if } 9 / 84 \leq t \leq 7 / 85 \\
0 \text { otherwise }
\end{array}\right. \\
T 2_{i t} & =\left\{\begin{array}{l}
1 \text { if } 8 / 85 \leq t \leq 9 / 86 \\
0 \text { otherwise },
\end{array}\right. \\
T 3_{i t} & =\left\{\begin{array}{l}
1 \text { if } 10 / 86 \leq t \leq 9 / 87 \\
0 \text { otherwise }
\end{array}\right.
\end{aligned}
$$

\footnotetext{
${ }^{4}$ Similar arguments could possibly be made with respect to other regressors. In preliminary estimation, milk price and income were tested for structural change and no changes were apparent.
} 
Then, letting LN denote natural logs,

$$
\begin{aligned}
A D V 1_{i t} & =\mathrm{LN} D A D V_{i t} * T 1_{i t} \\
A D V 2_{i t} & =\mathrm{LN} D A D V_{i t} * T 2_{i t} \\
A D V 3_{i t} & =\mathrm{LN} D A D V_{i t} * T 3_{i t} \\
T T 1_{i t} & =\mathrm{LN} T I M E_{i t} * T 1_{i t} \\
T T 2_{i t} & =\mathrm{LN} T I M E_{i t} * T 2_{i t} \\
T T 3_{i t} & =\mathrm{LNTIME} E_{i t} * T 3_{i t} .
\end{aligned}
$$

\section{Fluid Milk Advertising Model}

Using the lag structure and structural shifts noted above, the advertising model is specified in equation (3). The coefficients for the adjustments in advertising and time effects are designated using $\delta$ 's and $\alpha$ 's, while all other coefficients are denoted with $\beta$ 's.
LNMLKP and LNDINC, respectively, are attributed to regional variation.

In order to exploit the regional variation of the independent variables to increase the precision of the estimates of the impact of price, income, and advertising, the data were pooled. With the current data set and the nature of regional variability, pooling is preferred, although unbiasedness of the estimates is potentially traded off to gain greater precision.

\section{Estimated Advertising Model}

Table 1 provides the estimates for equation (3) along with several summary statistics. There are 106 observations per region for a total of $1,272 .{ }^{5}$ The mean square error $(M S E)$, percentage mean square error (PRMSE), and mean

$$
\begin{aligned}
& \mathrm{LNMLKQ_{it }}=\beta_{0}+\beta_{1} \mathrm{LNMLKP_{it }}+\beta_{2} \mathrm{LNOJPR}_{i t}+\beta_{3} \mathrm{LNDINC}_{i t}+\beta_{4} \mathrm{LNNU18_{it }} \\
& +\beta_{5} \mathrm{LNFEML} L_{i t}+\beta_{6} \mathrm{LNBLCK_{it }}+\beta_{7} \mathrm{LNRURL_{it }}+\beta_{8} \mathrm{LNFMSZ} Z_{i t} \\
& +\beta_{9} \mathrm{LNSCHL} L_{i t}+\beta_{10} D J A N_{i t}+\beta_{11} D F E B_{i t}+\beta_{12} D M A R_{i t}+\beta_{13} D A P R_{i t} \\
& +\beta_{14} D M A Y_{i t}+\beta_{15} D J U N_{i t}+\beta_{16} D J L Y_{i t}+\beta_{17} D A U G_{i t}+\beta_{18} D S E P_{i t} \\
& +\beta_{19} D O C T_{i t}+\beta_{20} D N O V_{i t}+\delta_{1} \mathrm{LNDADV} V_{i t}+\delta_{2} A D V 1_{i t}+\delta_{3} A D V 2_{i t} \\
& +\delta_{4} A D V 3_{i t}+\alpha_{1} \mathrm{LNTIME}_{i t}+\alpha_{2} T T 1_{i t}+\alpha_{3} T T 2_{i t}+\alpha_{4} T T 3_{i t}+\epsilon_{i t} \text {. }
\end{aligned}
$$

Equation (3) is a cross-sectional time-series model. Each cross section is assumed to be characterized by first-order autocorrelation with the additive error term on the first-order process contemporaneously correlated with the error term from other cross sections [i.e., $E\left(\epsilon_{i t}^{2}\right)=\sigma_{i i}, E\left(\epsilon_{i t} \epsilon_{k t}\right)=\sigma_{i k}$, and $\epsilon_{i t}=p_{i} \epsilon_{i(t-1)}+$ $\left.\mu_{i t}.\right)$. The model is estimated using the procedure outlined in Judge et al. (pp. 488-89) that utilizes the first-period observation.

\section{Pooling or Separate Equations}

In preliminary estimation all the coefficients of precursor models to (3) were allowed to vary by region. One model assumed a set of seemingly unrelated regressions and another was a Swamy random coefficient model. In both cases, many of the estimated coefficients were unacceptable with respect to prior beliefs. The failure of such models is due largely to problems with data variability within regions. Moreover, much of the variability of the independent variables is across regions. For example, $59 \%$ of the variability in LNDADV is attributable to differences in regions. Similarly, $60 \%$ and $76 \%$ of the variation for absolute error (MABSER) are reported in table 1. A value for $\Gamma$ giving the minimum $M S E$ is .0015 [see equation (1)]. Parameter estimates were quite robust over a wide range of $\Gamma$ values. The model explains regional differences as well as consumption variation within each region, and most of the coefficients have their expected signs. As shown in table 2, the means of the residuals within each region (adjusted for autocorrelation) are significantly different from zero in only four of the twelve regions. The $M A B S E R$ s for those four regions are not substantially different from those of the other eight regions, so the impact of a nonzero mean for these regions on the overall estimates is likely quite modest (see table 2). In addition, the adjusted residuals are shown to fail a randomness test in only four of the

\footnotetext{
5 The variable $T I M E$ was defined to range from 48 to 153 , instead of 1 to 106 . The original data set included observations prior to December 1987. However, there were numerous missing values for some regions for these earlier periods. For this reason, the analysis was started with the data at time period 48 (or Dec. 1978). We have left time in the model using this range (i.e., 48 to 153) in order to maintain continuity with other less technical discussions of these results. The model was, however, estimated letting time range from 1 to 106 with little difference between the estimates.
} 
Table 1. Pooled Cross-Sectional Time-Series Estimates for the Fluid Milk Model with Dependent Variable LNMLKQ Equation (3)

\begin{tabular}{|c|c|c|c|c|c|}
\hline Variables & \multicolumn{3}{|c|}{ Parameters } & S.D. & $t$-test \\
\hline INTCPT & \multicolumn{3}{|c|}{5.65262133} & 0.38138274 & 14.82138740 \\
\hline $\mathrm{LN} M L K P$ & & \multicolumn{2}{|c|}{-0.15342271} & 0.01759971 & -8.71734570 \\
\hline LNOJPR & & \multicolumn{2}{|c|}{-0.04617795} & 0.02548293 & -1.81211287 \\
\hline LNDINC & & \multicolumn{2}{|c|}{0.29344200} & 0.03001476 & 9.77659000 \\
\hline$N U 18$ & & \multicolumn{2}{|c|}{0.85893679} & 0.05526062 & 15.54337881 \\
\hline$F E M L$ & & \multicolumn{2}{|c|}{2.51337032} & 0.35795947 & 7.02138239 \\
\hline$B L C K$ & & \multicolumn{2}{|c|}{-0.09673090} & 0.00291692 & -33.16203713 \\
\hline$R U R L$ & & \multicolumn{2}{|c|}{-0.03254728} & 0.00449644 & -7.23845292 \\
\hline$F M S Z$ & & \multicolumn{2}{|c|}{0.57272183} & 0.04718087 & 12.13885607 \\
\hline$S C H L$ & & \multicolumn{2}{|c|}{-0.65731910} & 0.10620256 & -6.18929605 \\
\hline$D J A N$ & & \multicolumn{2}{|c|}{0.03352358} & 0.00289598 & 11.57588872 \\
\hline$D F E B$ & & \multicolumn{2}{|c|}{0.02867422} & 0.00372832 & 7.69092839 \\
\hline$D M A R$ & & \multicolumn{2}{|c|}{0.03117079} & 0.00417642 & 7.46351981 \\
\hline$D A P R$ & & \multicolumn{2}{|c|}{0.01178703} & 0.00444030 & 2.65455760 \\
\hline$D M A Y$ & & \multicolumn{2}{|c|}{-0.01372270} & 0.00459420 & -2.98696395 \\
\hline$D J U N$ & & \multicolumn{2}{|c|}{-0.06454313} & 0.00467400 & -13.80897650 \\
\hline$D J L Y$ & & \multicolumn{2}{|c|}{-0.07569171} & 0.00467231 & -16.20005600 \\
\hline$D A U G$ & & \multicolumn{2}{|c|}{-0.03808416} & 0.00462408 & -8.23604420 \\
\hline$D S E P$ & & \multicolumn{2}{|c|}{0.02448563} & 0.00432253 & 5.66464938 \\
\hline$D O C T$ & & \multicolumn{2}{|c|}{0.03465499} & 0.00387606 & 8.94077977 \\
\hline DNOV & & \multicolumn{2}{|c|}{0.02295260} & 0.00304161 & 7.54619863 \\
\hline LNDADV & & \multicolumn{2}{|c|}{0.01127914} & 0.00276279 & 4.08251947 \\
\hline$A D V 1$ & & \multicolumn{2}{|c|}{0.00598299} & 0.00550942 & 1.08595553 \\
\hline$A D V 2$ & & \multicolumn{2}{|c|}{0.02037743} & 0.00831730 & 2.45000567 \\
\hline$A D V 3$ & & \multicolumn{2}{|c|}{0.02112023} & 0.00847017 & 2.49348500 \\
\hline LNTIME & & -0.038879 & & 0.01371343 & -2.83511573 \\
\hline$T T 1$ & & 0.014773 & & 0.01306850 & 1.13045446 \\
\hline$T T 2$ & & 0.048336 & & 0.01861414 & 2.59674881 \\
\hline$T T 3$ & & 0.053561 & & 0.01934076 & 2.76933787 \\
\hline Estimated & es of Rho & & & & $\mathrm{N} F \mathrm{C}-12$ \\
\hline Region & $\operatorname{rho}(p)$ & Region & $\operatorname{rho}(p)$ & & $\begin{array}{l}\text { No. of } C S=12 \\
\text { No. of } T S=106\end{array}$ \\
\hline$C A L$ & 0.7200 & $M I C$ & 0.9602 & & $T 1=9 / 84-7 / 85$ \\
\hline$C O L$ & 0.6447 & $E N G$ & 0.8199 & & $(T I M E=117$ to 128$)$ \\
\hline$F L A$ & 0.6696 & $A T L$ & 0.8286 & & $T 2=8 / 85-9 / 86$ \\
\hline$G B S$ & 0.6574 & $T E X$ & 0.7042 & & $(T I M E=129$ to 141$)$ \\
\hline$G E O$ & 0.5479 & $U M W$ & 0.6823 & & $T 3=10 / 86-9 / 87$ \\
\hline$K A N$ & 0.8113 & $V I R$ & 0.7883 & & $\begin{array}{l}(T I M E=142 \text { to } 153) \\
(T I M E=48-153)\end{array}$ \\
\hline$R^{2}$ & $M S E$ & & PRMSE & MABSER & Total no. obs. $=1,272$ \\
\hline 0.9084 & .0020456 & & 2.0387 & 0.0170 & $\Gamma=.0015$ \\
\hline
\end{tabular}

twelve regions. Given these statistics, the coefficient estimates are judged reasonable and acceptable for further analysis.

\section{Interpretation of Coefficient Estimates}

Income and the milk price elasticities have the expected signs and are statistically significant at the $99 \%$ confidence level. Both values are within a reasonable range of prior studies with the price elasticity equalling -.1534 and the income elasticity estimated to be .2934 (Kinnucan, Liu and Forker, Ward and McDonald). The effects of orange juice on milk consump- tion suggest weak complementarity with a small negative coefficient of -.0461 . This elasticity is not significant at the $5 \%$ level. The seasonality parameters are consistent with most other milk demand studies. Note the sizable decline during the summer months along with the rapid increase with the start of fall.

The demographic variables are highly significant. Milk consumption is clearly shown to be lower among the $B L C K$ group. The demographic variable with the greatest rate of change over time is $N U 18$; it is declining as the U.S. population ages. The coefficient $N U 18$ is positive and very significant. Much of the secular trend toward declining per capita consumption 
Table 2. Validation Statistics for the Estimated Model by Region

\begin{tabular}{lccrr}
\hline Regions & $M A B S E R$ & $M S E$ & ZMEAN & \multicolumn{1}{c}{ ZRUN } \\
\hline CAL & 0.0169 & 0.0005 & 4.3869 & 0.7808 \\
COL & 0.0175 & 0.0005 & -1.4065 & 3.5134 \\
$F L A$ & 0.0224 & 0.0009 & -1.8856 & -1.5615 \\
GBS & 0.0182 & 0.0006 & -0.4879 & -0.1952 \\
GEO & 0.0176 & 0.0005 & 0.3669 & 0.7808 \\
KAN & 0.0157 & 0.0004 & -1.0413 & -0.5856 \\
MIC & 0.0140 & 0.0003 & 2.6169 & 0.1952 \\
ENG & 0.0144 & 0.0004 & 2.5179 & 2.5375 \\
ATL & 0.0139 & 0.0003 & 1.0351 & 2.7326 \\
TEX & 0.0154 & 0.0005 & -2.1412 & 1.3663 \\
UMW & 0.0145 & 0.0003 & -0.1676 & 2.5375 \\
VIR & 0.0233 & 0.0010 & -0.6755 & 0.7808 \\
\hline
\end{tabular}

Note: All statistics are computed on $\hat{\mu}_{i t}$, the additive error term of the first-order autoregressive process. These residuals are computed using the estimates in table 1 for eq. (3). The four statistics computed for each region are mean absolute error $(M A B S E R)$, mean square error $(M S E)$, a test of the hypothesis that the mean of the error terms in each region is equal to zero (ZMEAN), and a test of the hypothesis that the error terms have a random distribution (ZRUN). ZMEAN and ZRUN have a standard normal distribution.

of fluid milk is undoubtedly caused by this factor. The effect of average level of education $(S C H L)$ is negative, and the proportion of one person households (FMSZ) is positive. These unexpected signs are partly caused by the limited variability of these variables over time and across regions. They may also indicate a concern of more educated consumers about fat and the use of milk as a convenience food by single-person households. Nonetheless, the demographic variables still serve the role of representing differences in consumption across regions.

The advertising coefficients have the expected signs and are statistically significant at the $99 \%$ level except for $A D V 1$. The coefficient for $\mathrm{LN} D A D V$ reflects the effects of advertising in the pre-act months (i.e., before September 1984). During the first year of the post-act period [see equation (2a)], some shift in the advertising parameter was hypothesized, although the extent of such shifts was expected to be small because the Board was just starting. The advertising effect during the first year of the post-act period is the sum of the coefficients for $L N D A D V$ and $A D V 1$ or $\left(\delta_{1}\right.$ $+\delta_{2}$ ) in equation (3). Parameters for the second and third periods are the coefficients for LNDADV and $A D V 2\left(\delta_{1}+\delta_{3}\right)$, and LNDADV and $A D V 3\left(\delta_{1}+\delta_{4}\right)$, respectively. The estimates for both $\delta_{3}$ and $\delta_{4}$ are positive and statistically different from zero at a $95 \%$ level of confidence. The empirical results clearly indi- cate structural shifts through increases in the advertising parameters during the second and third years of the Board's programs. The coefficient values for the later two periods (August 1985-September 1986 and October 1986-September 1987) suggest little difference in the advertising coefficients. These results indicate that a higher plateau in advertising parameter estimates occurred following the pre-act periods. Whether this is permanent or transitory will become evident only in the future.

The variable TIME accounts for other longterm adjustments in fluid milk consumption. If the post-act activities led to definite changes in consumption habits, then the pre-act trends are likely to have changed. The coefficient for LNTIME in equation (3) is for the pre-act months, while the coefficients for $T T 1, T T 2$, and TT3 represent adjustments occurring in the post-act periods (see equations $2 \mathrm{~d}, 2 \mathrm{e}$, and 2f). The results in table 1 show that during the first year of the post-act months, the shift (TT1) is not statistically different from zero. However, both $T T 2$ and TT3 coefficients are significant at the $99 \%$ confidence level. During the pre-act periods, the time trend gave a negative value of -.0389 . During the first year of the post-act, the trend coefficient changed to -.0241 . In the subsequent two post-act years, the estimates indicate a reversal in the negative time trend with parameter shifts to .0095 and .0147 , respectively. While one cannot conclusively and exclusively attribute these time shifts to the act, it likely played an important role. Another contributing factor could have been the increased awareness of the importance of calcium in the diet.

Overall, the advertising and time coefficients show that: (a) fluid milk advertising had a positive and statistically significant impact on fluid milk consumption; $(b)$ the effectiveness of fluid milk advertising increased during the post-act periods; $(c)$ the negative trend in per capita consumption of fluid milk was reversed; and $(d)$ the aging of the U.S. population is having a significant effect on per capita milk consumption.

\section{Simulated Impact of Milk Advertising}

Simulation procedures are used to evaluate the gains attributed to fluid milk advertising. Fluid milk per capita consumption is first predicted given the actual observations for all 
Table 3. Summary of Model Simulation Results on the Effects of Genetic Advertising on Fluid Milk Sales for Direct Consumption in the Twelve Study Regions

\begin{tabular}{|c|c|c|c|c|c|c|c|c|c|c|c|}
\hline & \multicolumn{3}{|c|}{ Fluid Milk Advertising Expenditures } & \multicolumn{4}{|c|}{ Simulated Gains to Advertising } & \multirow{2}{*}{\multicolumn{2}{|c|}{ Fluid Milk Sales }} & \multirow{2}{*}{\multicolumn{2}{|c|}{ Gains Due to }} \\
\hline & \multirow{2}{*}{$\begin{array}{l}\text { Regional } \\
\text { Programs }\end{array}$} & \multirow{2}{*}{$\begin{array}{c}\text { NDPB } \\
\text { Programs }\end{array}$} & \multirow{2}{*}{$\begin{array}{c}\text { Total } \\
\text { Twelve } \\
\text { Regions }\end{array}$} & \multirow{2}{*}{$\begin{array}{c}\text { NDPB } \\
\text { (\% Share) }\end{array}$} & \multirow{2}{*}{$\begin{array}{l}\text { Due to } \\
\text { Adver- } \\
\text { tising }^{\mathrm{a}}\end{array}$} & \multirow{2}{*}{$\begin{array}{l}\text { Simulated } \\
\text { Post- } \\
\text { Advertising }\end{array}$} & \multirow{2}{*}{$\begin{array}{c}\text { Structural } \\
\text { Effect }^{\mathrm{c}}\end{array}$} & & & & \\
\hline & & & & & & & & Total & Estimated & Advertising & Post-Act \\
\hline Col 1 & Col 2 & Col 3 & Col 4 & Col 5 & Col 6 & Col 7 & Col 8 & Col 9 & Col 10 & Col 11 & Col 12 \\
\hline Pre-act ${ }^{\mathrm{d}}$ & ------ & $-\quad(\$) \quad-$ & $--\cdots-\cdots$ & (\%) & $-\cdots--$ & ----- & (mil. lbs.) & ----- & $---\cdots$ & $----(\%)$ & $\cdots-$ \\
\hline $12 / 78-08 / 84$ & $90,442,848$ & 0 & $90,442,848$ & & $\begin{array}{c}3,914.5 \\
(1,032.6)\end{array}$ & & & $124,588.7$ & $122,380.4$ & 3.20 & \\
\hline Post-act & & & & & & & & & & & \\
\hline $09 / 84-09 / 87$ & $43,692,559$ & $32,600,800$ & $76,293,359$ & 42.73 & $\begin{array}{c}4,384.6 \\
(1,081.1)\end{array}$ & $\begin{array}{r}1,726.3 \\
(392.5)\end{array}$ & $\begin{array}{r}1,348.9 \\
(579.3)\end{array}$ & $69,112.4$ & $67,836.2$ & 6.46 & 2.54 \\
\hline $\begin{array}{l}\text { Total } \\
12 / 78-09 / 87\end{array}$ & $134,135,407$ & $32,600,800$ & $166,736,207$ & & $\begin{array}{c}8,299.1 \\
(1,648.0)\end{array}$ & & & $193,701.1$ & $190,216.6$ & 4.36 & \\
\hline
\end{tabular}

Note: Simulation based on assuming the model with kappa $=.0015$. See model in table 1 .

a Total advertising gains are calculated by subtracting estimated sales without advertising from estimated total sales with all advertising

b Simulated post-act advertising gains are calculated by first estimating sales assuming that the advertising would have remained at the same level as in $9 / 83-8 / 84$

( $\$ 18.5$ million) if the act had not been passed. These estimated sales are then subtracted from the estimated total sales with all advertising included.

c The structural gains represent those sales gains attributable to the coefficient shifts in the post-act months.

d Values in parentheses are standard error of the figures directly above. See Ward and Dixon (1988) for method of calculation.

independent variables, column 10 in table 3. These predicted per capita values are then converted to total pounds of fluid milk consumed in each month and region. Using the same model in table 1, sales are then predicted using a number of different advertising scenarios. The total effects of all advertising are first computed. Sales are estimated assuming no advertising beyond the goodwill captured by the goodwill $\Gamma$ value and then subtracted from the predicted sales given actual observations over all independent variables.

A second simulation is performed to measure the impact of the act during the post-act years. This is accomplished by assuming that in the absence of the act regional advertising would have remained at the nominal level of $\$ 18.5$ million observed from September 1983-August 1984, i.e., the last year before the act. The $\$ 18.5$ million is distributed over time and regions similarly to the distribution in September 1983-August 1984 . It is also assumed that the coefficients of advertising and time would have remained equal to their preact values throughout the post-act periods. Regional expenditures declined after the Board started, and the analysis in this section implicitly assumes such declines would not have occurred in the absence of the act. Predicted sales using this assumption are subtracted from predicted values using actual post-act advertising levels (column 10, table $3)$.

In the third simulation post-act sales gains attributable to structural shifts are computed. Recall that the model in table 1 reflects structural shifts with $A D V 1, A D V 2$, and $A D V 3$ for advertising and $T T 1, T T 2$, and $T T 3$ for the time trends. These gains due to structural shifts are calculated by predicting sales using actual independent variable values assuming no structural shifts. These sales are subtracted from those predicted assuming structural shifts (column 10). The difference is the gain in sales attributed to structural shifts.

Detailed results from using the estimated model to measure the gains from fluid milk advertising three simulations are reported in table 3. The table is divided into the pre- and post-act periods as shown in column 1 . Columns 2, 3, and 4 give the total expenditures for the regions and the Board. Column 3 is the Board expenditure prorated to the twelve regions. Column 5 shows the percentage of the Board's total national expenditures on fluid milk that are prorated to the equivalent level for each region. Because the study is based on sales within the twelve regions, it is necessary to attribute this prorated share of national expenditures to the regions being considered. Column 9 shows actual sales, and column 10 shows predicted sales using the observed 
data. Columns 6,7 , and 8 report the gains due to advertising under the three different scenarios. Columns 11 and 12 show the gains in columns 6 and 7, respectively, as a percent of estimated sales (column 10).

Column 6, table 3 gives the estimated gains in fluid milk sales due to all advertising for the pre- and post-act months. Pre-act gains from advertising were about 56.5 million pounds per month (or total of 3.9 billion pounds) while the post-act levels reached 118 million pounds per month (or a total of 4.38 billion pounds). The post-act gains represent the aggregate effect of both regional and Board programs. For the pre-act periods, the average gain per dollar of advertising was around 43 pounds. In contrast, the average gain per advertising dollar in the post-act periods was 57.5 pounds. Comparing these two averages suggests some improvement in the relative gains between the pre- and post-act periods. While these values provide useful insights into the advertising impact, they must be used with caution because both are averages and ignore the marginal gains to advertising expenditure patterns.

Column 7 in table 3 shows the predicted sales gains due to the act as computed in the second simulation. Sales gains of 1.7 billion pounds are attributed to the act, given the assumed post-act regional expenditures. Those gains estimated for the post-act periods in columns 6 and 7 reflect the advertising expenditures and the shifts in the demand parameters initially defined in equation (2). It is important to determine how much of the gain in column 7 is from advertising expenditure increases versus structural change. The results of simulation three in column 8 , table 3 , shows the sales gains that are directly related to the structural change, i.e., the shifts in the advertising and time coefficients. Most of the simulated gains shown in column 7 are caused by parameter adjustments rather than advertising increases over the $\$ 18.5$ million regional level used as the simulated base (i.e., compare columns 7 and 8 ). These results support the hypothesis that national campaigns made advertising dollars more effective.

Finally, columns 11 and 12 express the estimated sales gains in relative terms. During the post-act periods, all fluid milk advertising increased fluid milk sales by $6.46 \%$ relative to milk sales without the advertising effort (see column 11). Under the assumption of continued regional ad rertising at the pre-act levels, the act's impact increased fluid milk consumption by $2.54 \%$.

\section{Marginal Advertising Gains}

The above analysis does not give the impact of marginal expenditures for advertising. To have an estimate of changes in advertising, marginal sales responses are computed. Measurement of the marginal gains depends on the advertising increments and the regional and time distribution of the expenditures. Given actual advertising expenditures recorded in table 3 , column 4 , one measure of the marginal responses is the estimated total sales given incremental percentage decreases and increases in the actual expenditure level during the post-act period. For example, what would be the estimated sales throughout the post-act months if advertising were only $25 \%$ of the actual level or $50 \%$ greater than the actual? Using this method, the calculated gains account for both the immediate and longer-term carryover effects except for the carryover extending beyond 9/87. Different marginal responses could be achieved by redistributing funds across regions and/or over time. Table 4 displays the incremental adjustments in the overall post-act expenditures and provides the marginal responses. The index equalling 1.00 denotes the actual levels shown in table 3 for the post-act months, i.e., $\$ 76.3$ million. If expenditures were only $25 \%$ of the base, total fluid milk sales would have be 64.6 billion pounds for the twelve regions. In contrast, advertising levels $75 \%$ above the base give

Table 4. Estimated Marginal Fluid Milk Sales Gains Associated with Incremental Increases in the Post-Act Generic Advertising

\begin{tabular}{|c|c|c|c|c|}
\hline $\begin{array}{l}\text { Proportion } \\
\text { of Actual }\end{array}$ & $\begin{array}{c}\text { Post-act } \\
\text { Advertising }\end{array}$ & $\begin{array}{l}\text { Total } \\
\text { Sales }\end{array}$ & $\begin{array}{c}\text { Marginal } \\
\text { Gains }\end{array}$ & $\begin{array}{c}\text { Pounds } \\
\text { per } \\
\text { Dollar }\end{array}$ \\
\hline & $(\$)$ & (mil. lbs.) & (bil. lbs.) & (lbs.) \\
\hline 0.25 & $19,073,330$ & $64,622.0$ & & \\
\hline 0.50 & $38,146,661$ & $66,009.4$ & 1.3874 & 72.740 \\
\hline 0.75 & $57,219,990$ & $67,026.5$ & 1.0171 & 53.326 \\
\hline 1.00 & $76,293,359$ & $67,836.2$ & 0.8097 & 42.452 \\
\hline 1.25 & $95,366,699$ & $68,511.8$ & 0.6756 & 35.421 \\
\hline 1.50 & $114,439,940$ & $69,092.7$ & 0.5809 & 30.456 \\
\hline 1.75 & $133,513,379$ & $69,603.3$ & 0.5106 & 26.770 \\
\hline
\end{tabular}

Note: See table 3 for the actual base corresponding to $100 \%$ base 
sales of 69.6 billion pounds. The declining marginal gains are apparent in this table. Marginal gains drop from 1.38 billion pounds to .51 billion pounds over the expenditure ranges evaluated. Furthermore, the average pounds of gains per advertising dollar drop from a high of 72 pounds per advertising dollar to a low of 26.7 pounds per dollar at the highest expenditure level.

\section{Conclusion}

The results of this study confirm a statistically significant relationship between fluid milk consumption and generic fluid milk advertising as found in previous studies. Moreover, demographic variables are highly significant and help explain both regional variation and longterm changes. The demographic variable changing most rapidly, age distribution, indicates a decline in per capita consumption rate. Because little can be done to alter this decline except in the long run, dairy advertising policies must respond in some way to this effect. Greater emphasis on calcium concerns may be a way to exploit this factor.

The estimated varying coefficient model shows that the institution of The Dairy and Tobacco Adjustment Act (via the National Dairy Board) has contributed to an increase in consumer responsiveness to fluid milk advertising. Simulated gains in fluid milk sales per advertising dollar were higher in the post-act period. Shifts in consumption responses related directly to milk advertising and longterm trends are statistically significant. These shifts reflect underlying changes in consumer preferences for dairy products. This study indicates that the increase in consumption from advertising is more a function of a national campaign, as opposed to regional efforts, than an increase in total advertising expenditures. This conclusion is supported by the significant shifts in both the advertising and time-trend coefficients. Furthermore, the simulations clearly showed increases in the average return per dollar of advertising in the post-act periods compared to the pre-act years.

An important implication of these results is whether other generic commodity programs would benefit by a national campaign. For the dairy industry, the results are supportive of the national program. The methodology is useful to other generic commodity analysis.
However, attempting to extrapolate these results to other commodities is at best risky. In the broadest sense, the success of any program will depend on three major conditions, i.e., the characteristics of the commodity, consumers' knowledge about the commodity, and the quality and intensity of the advertising programs. These conditions generally differ considerably across commodities and thus potentially lead to different results.

\section{[Received July 1987; final revision received December 1988.]}

\section{References}

Bozgodan, K., et al. "Econometric Analyses of the Effect of Generic Advertising on Fluid Milk, Cheese and Butter Demand." Report to National Dairy Promotion and Research Board, A. D. Little, Inc. May 1986, Reference 53630.

Frank, M. D. "Structural Change in the Retail Demand for Beef, Chicken and Pork: An Application of Gradual Switching Regression." Ph.D. thesis, University of Illinois, 1984.

Goodhart, R. S., and M. E. Shils, eds. Modern Nutrition in Health and Disease, 6th ed. Philadelphia: Lea and Febigen, 1980.

Judge, G. G., W. E. Griffiths, R. C. Hill, H. Lutkepohl, and T. C. Lee. The Theory and Practice of Econometrics, 2nd ed. New York: John Wiley \& Sons, 1985.

Kinnucan, H. "Demographic Versus Media Advertising Effects on Milk Demand: The Case of the New York City Market." Northeastern J. Agr. and Resour. Econ. 5(1986):66-74.

Kinnucan, H., and O. D. Forker. "Seasonality in the Consumer Response to Milk Advertising with Implications for Milk Promotion Policy." Amer. J. Agr. Econ. 68(1986):562-71.

Liu, Donald J., and Olan D. Forker. "Generic Fluid Milk Advertising, Demand Expansion, and Supply Response: The Case of New York City.' Amer. J. Agr. Econ. 70(1988):229-36.

Swamy, P. A. V. B. "Efficient Inference in a Random Coefficient Regression Model." Econometrica 38(1970):311-23.

Thompson, S. R., and D. A. Eiler. "Determinants of Milk Advertising Effectiveness." Amer. J. Agr. Econ. 59(1977):330-35.

U.S. Department of Agriculture. Report to Congress on the Dairy Promotion Program. Washington DC, 1 July 1986.

Ward, Ronald W. Milk Advertising Ten Market Study. Report to United Dairy Industry Association, University of Florida, 3 Dec. 1984. 
Ward, R. W., and J. Davis. "A Pooled Cross-Section Time-Series Model of Coupon Promotions." Amer. J. Agr. Econ. 60(1978):393-410.

Ward, R. W., and B. L. Dixon. "An Econometric Analysis of the National Dairy Promotion Board's Fluid Milk Advertising Programs." Report to the National Dairy Promotion and Research Board. Ariington VA, 1 March 1987.

. "The Economic Impact of Fluid Milk Advertising on Milk Consumption.' National Dairy Promotion and Research Board, University of Florida, 15 March 1988.

Ward, R. W., and W. F. McDonald. "Effectiveness of Generic Milk Advertising: A Ten Region Study." Agribusiness 2(1986):77-79.

Ward, R. W., and L. H. Myers. "Advertising Effectiveness and Coefficient Variation Over Time." Agr. Econ. Res. 31(1979):1-11. 